\title{
INSPEKSI GETARAN PADA TURBIN UAP PENGGERAK POMPA DI INDUSTRI PUPUK
}

\author{
Budiawan I, Raharjo P*, Prasetyo \\ Jurusan Teknik Mesin Politeknik Negeri Bandung \\ Email: parno_raharjo@yahoo.com \\ *Corespondent Author
}

\begin{abstract}
Abstrak
Turbin uap di industri memiliki tingkat kritis tinggi sehingga diperlukan penerapan teknik predictive maintenance. Teknik yang handal untuk turbin uap adalah inspeksi getaran mesin. Dengan teknik inspeksi getaran mesin, gejala kerusakan dapat dideteksi secara dini dan kerusakan lebih lanjut dapat dicegah. Obyek inspeksi yaitu turbin uap yang digunakan turbin menggerakkan pompa melalui transmisi kotak roda gigi. Parameter yang diukur dan dianalisa meliputi overall amplitude, sinyal dan spektrum getaran. Analisanya menggunakan comparative, trending dan descriptive analysis. Berdasarkan overall amplitude menunjukkan bahwa turbin dalam keadan baik dan cenderung memuaskan. Pada turbin terdapat sinyal yang fluktuatif. Pada spektrum nampak frekuensi fundamental turbin dan pompa berikut frekuensi harmoniknya. Amplitudo tertinggi kemungkinan disebabkan karena gearmeshing problem. Amplitudo pada frekuensi $366.2 \mathrm{~Hz}$ belum diketahui dari mana berasal. Oleh karena itu diperlukan kajian lebih lanjut terutama pada kotak roda gigi.
\end{abstract}

Kata Kunci : "predictive maintenance”, “inspeksi getaran”, “overall amplitude”, "frekuensi fundamental”, "frekuensi harmonik".

\section{Pendahuluan}

Turbin uap merupakan sebuah mesin yang berfungsi untuk mengkonversikan energi panas dari uap air menjadi energi mekanik dalam bentuk putaran poros turbin. Turbin uap digunakan di industri seperti industri pembangkit, industri pupuk dan industri minyak sawit. Di industri pupuk turbin uap digunakan untuk menggerakkan pompa dan juga juga menggerakkan kompresor piston. Turbin uap merupakan mesin yang memiliki tingkat kritis yang tinggi, artinya jika mesin ini mengalami gangguan atau kerusakan akan mengakibatkan kerugian besar baik materiil dan moril serta keselamatan kerja. Oleh karena itu agar turbin uap tidak terjadi kerusakan secara tiba tiba diperlukan penerapan preventive maintenance. Dengan penerapan preventive maintenance gejala kerusakan dapat dideteksi sedini mungkin dan kerusakan lebih lanjut dapat diatasi sehingga kerugian yang lebih besar akibat berhentinya mesin secara tiba tiba dapat diatasi. Dalam aplikasinya preventive maintenance dapat dilakukan secara scheduled maintenance dan predictive maintenance. Salah satu teknik predictive maintenance yang handal untuk rotating mesin seperti turbin uap adalah teknik monitoring atau inspeksi getaran.

\section{Tinjauan Pustaka}

\subsection{Turbin uap}

Turbin uap merupakan konversi energi yang mengkonversikan energi potensial uap menjadi energi mekanik pada poros turbin. Energi potensial uap sebelum dikonversikan menjadi energi mekanik terlebih dahulu dikonversikan menjadi energi kinetik dalam nozel (pada turbin impuls) atau dalam nozel dan sudu-sudu gerak (pada turbin reaksi). Turbin uap dikenal sebagai pembangkit daya yang dapat diandalkan dan serba guna. Berdasarkan penggunaannya turbin uap dibagi menjadi tiga diantaranya steam turbine generator set yaitu turbin uap yang dihubungkan dengan generator untuk membangkitkan listrik, turbin uap kapal yaitu turbin uap yang digunakan sebagai penggerak utama kapal, dan turbin uap 
mekanik yaitu turbin uap yang digunakan di industri-industri sebagai penggerak mula kompresor dan pompa( Muin,1993).

Turbin uap yang digunakan untuk pompa bertingkat yang dihubungkan langsung menggunakan kopling flens fleksibel ditunjukkan seperti pada gambar berikut.

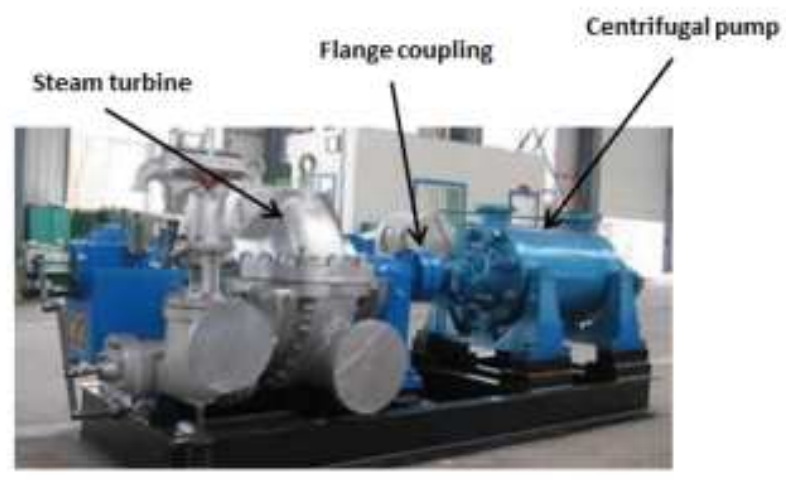

\section{Gambar 1. Turbin Uap Penggerak} Pompa(Thapliyal, 2017)

Bagian utama pada single stage impulse steam turbine antara lain Turbine Shaft (1), Governor Lever (2), Woodward TG Governor (3), Steam End Bearing Case (4), Sentinel Warning Valve (5), Exhaust End Bearing Case (6), Carbon Packing Rings (7), Steam Chest (8), Steam Strainer (9), Governor Valve Stem (10), Trip Lever (11), Oil Rings (12), Packing Case Leak offs (13), Turbine Wheels (14), Turbine Case (15), Hand Valve (16), Over speed Cup (17), Thrust Bearing (18), Main Bearings (19), Exhaust (20) dan Inlet (21), ditunjukkan seperti pada gambar berikut (Dresser Rand, 2013).

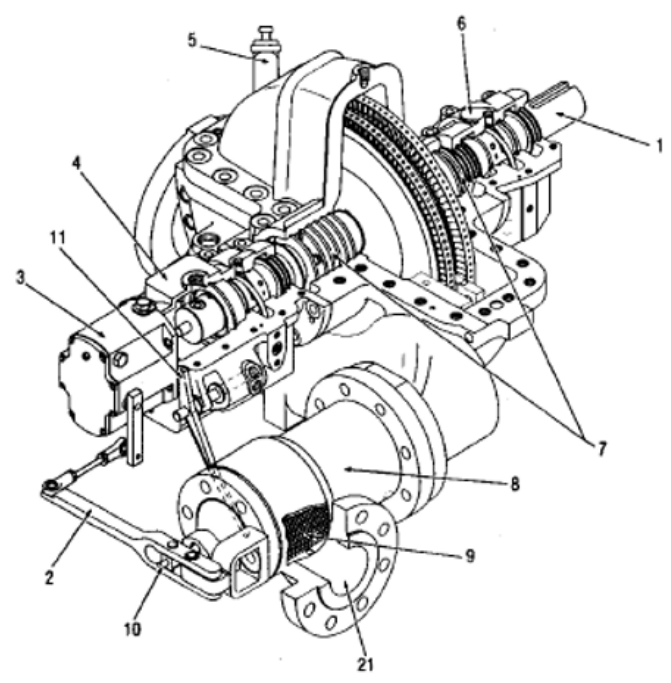

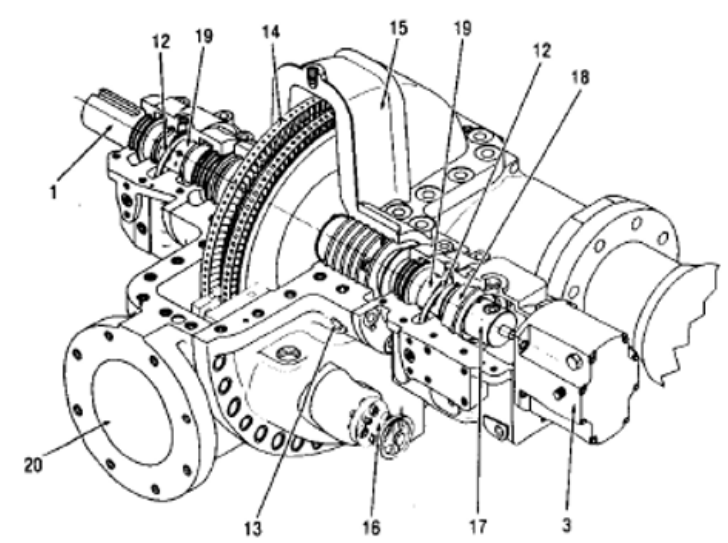

\section{Gambar2. Dresser Rand Single Stage Turbine(Dresser Rand, 2013)}

\subsection{Getaran pada turbin}

Turbin uap merupakan mesin pembangkit tenaga yang bagian utamanya adalah rotor yang berputar yang dihubungkan dengan kopling ke generator listrik. Rotor terdiri dari sudu sudu yang dipasang pada poros.

Getaran rotor turbin uap yang dapat mengakibatkan kerusakan yaitu rotor bending, rotor rubs, rotor and casing misalignment dan rotor unbalance (Shamoradi et al, 2013).

Pengukuran dan monitoring getaran mesin sudah banyak yang dilakukan, tetapi dalam kondisi dan konstruksi yang berbeda. Juan G.L dan kawan kawan melakukan pengukuran dan analisa getaran pada poros turbin uap 550 MWatt pada putaran 3000 rpm, karena pengaruh aliran uap. Pada pengukuran tersebut didapat bahwa getaran karena gaya aliran uap terjadi pada ujung rotor masukan uap. Ampliudo tertinggi terjadi pada frekuensi $28.15 \mathrm{~Hz}$. (Juan et al, 2013).

Ahmed dan kawan kawan melakukan monitoring kondisi turbin uap 210 MWat berdasarkan overall amplitude yang terjadi. Monitoring dilakukan selama 10 hari berturut turut. Monitoring menghasilkan bahwa amplitudo yang terjadi setiap waktu berubah. Besar amplitudo tidak sama antara arah horisontal, vertikal dan aksial. Amplitudo tinggi terjadi pada bantalan no 7 yang disebut sebagai tail bearing. (Ahmed et al, 2013). Monitoring ini tidak menyebutkan kondisi 
turbin dan tidak menganalisa menggunakan spektrum sehingga tidak diketahui sumber getaran yang terjadi.

Elmaati dan kawan kawan mengimplementasikan monitoring getaran pada turbin uap pada continous power 470 $\mathrm{kWatt}$ atau short term power $1380 \mathrm{kWatt}$ dalam rangka pemeliharaan yang optimum. Hasil implementasi menunjukkan bahwa monitoring getaran secara terus menerus perlu dilaksanakan dari pada hanya melakukan perbandingan pengukuran besarnya getaran. Selain dari pada itu dimungkinkan untuk mendifinisikan dan membangun sebuah peralatan yang cukup untuk monitoring getaran nirkabel agar mengurangi biaya pemeliharaan prediktif (Elmaati et al, 2013).

Pada monitoring ini tidak menjelaskan besarnya amplitudo yang terjadi dan tidak melakukan analisa vibration signal dan vibration spectrum yang digunakan untuk mengetahui sumber getaran yang terjadi.

\section{Metodologi}

\subsection{Obyek Pengujian}

Obyek pengujian inspeksi getaran yaitu sebuah turbin uap yang digunakan untuk menggerakkan pompa melalui gearbox di industri pupuk.

Turbinnya adalah steam turbine single stage single valve, $1030 \mathrm{~kW}$ dengan putaran 5098 rpm $(71.8 \mathrm{~Hz})$, tipe fondasinya kaku menggerakkan pompa sentrifugal bertingkat melalui kotak roda gigi yang putarannya $6500 \mathrm{rpm} \quad(108.33 \mathrm{~Hz})$. Instalasinya ditunjukkan seperti gambar berikut

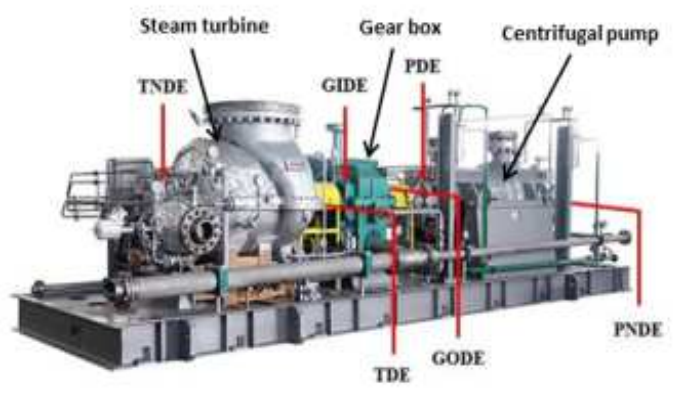

Gambar 3. Instalasi Turbin Uap (Elliot, 2014)

\subsection{Instrumentasi}

Peralatan ukur yang digunakan yaitu Vibscanner, digunakan untuk menginspeksi overall amplitude getaran pada turbin uap tersebut. Untuk mengetahui sinyal dan spektrum getaran pada turbin uap digunakan accelerometer CA-YD-185TNC yang dilengkapi dengan data acquisition model YE7600.

\subsection{Metode dan Titik pengukuran}

Untuk mengukur overall amplitude vibration menggunakan

vibscanner.Pengukurandilakukan tujuh kali selama 7 minggu. Untuk mengetahui karakteristik vibration signal dan vibration spectrum menggunakan data acquisition. Titik pengukurannya dilakukan pada bearing housing dari turbin uap, gearbox, dan pompa sentrifugal yang merupakan recycle solution feed pump.

Titik pengukuran pada turbin uap dilakukan pada bantalan turbine nondrive end arah horizontal, vertical dan axial (TNDEH, TNDEV dan TNDEA) serta pada bantalanturbine drive end arah horizontal dan vertical (TDEH dan TDEV).

\subsection{Metode analisis}

Untuk menentukan kondisi mesin dan karakteristik getaran yang terjadi yaitu analisis komparatif (comparative analysis), analisis deskriptif (descriptive analysis), dan analisis kecenderungan (trending analysis).

Analisis komparatif, ditentukan dengan cara membandingkan hasil inspeksi dengan standar yang telah ditentukan. Standar yang digunakan yaitu Vibration Severity Standard ISO 10816. Analisis trending, ditentukan dengan cara membandingkan hasil inspeksi dari waktu ke waktu.

Analisis deskripsi yaitu yaitu analisis dengan cara menguraikan penjelasan yang didasarkan pada amplitudo dan letak frekuensi amplitudo tersebut berada.

ISO 2372 (10816) merupakan pedoman untuk mengevaluasi batas getaran dalam suatu mesin yang beroperasi dalam rentang frekuensi $10-200 \mathrm{~Hz}(600-12000 \mathrm{rpm})$. Yang 
termasuk tipe mesin ini adalah mesin kecil, direct-coupled, electric motors and pumps, production motors, medium motors, generators, steam and gas turbines, turbocompressors, turbo-pumps and fans. Mesin dapat dikopel secara kaku dan fleksibel, atau dihubungkan dengan roda gigi. Sumbu poros putar dapat berarah horisontal, vertikal dan menyudut. Tenaga mesin dikelompokkan menjadi empat klas. Klas I adalah mesin kecil (tenagasampaidengan $15 \mathrm{~kW}$ ). Klas II adalah mesin menengah (tenaga15 hingga 15 $\mathrm{kW}$ ). Klas III adalah mesin besar dengan fondasi berat. Klas IV adalah mesin besar dan mesin turbo dengan fondasi khusus. Vibration severtity ISO 10816 ditunjukkan seperti tabel berikut.

\section{Tabel 1.Vibration Severity ISO 10816} (Reliability Direct, 2013)

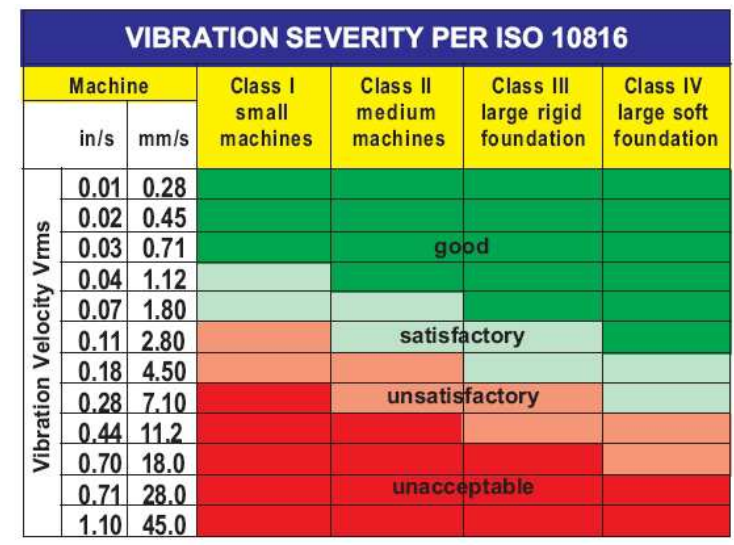

\section{Hasil Inspeksi dan Analisis}

\subsection{Hasil inspeksi overall amplitude}

Hasil pengukuran averall amplitude pada turbin uap selama 7 minggu berturut turut ditunjukkan seperti tabel berikut.

Tabel 2. Hasil pengukuran overall amplitude selama 7 minggu

\begin{tabular}{|c|l|c|c|c|c|c|c|c|}
\hline No & \multirow{2}{*}{$\begin{array}{c}\text { Titik } \\
\text { pengukuran }\end{array}$} & \multicolumn{7}{|c|}{ Hasil Pengujian (mm/s) RMS } \\
\cline { 3 - 9 } & & 1 & 2 & 3 & 4 & 5 & 6 & 7 \\
\hline 1 & TNDEH & 3,35 & 3,94 & 3,36 & 3,51 & 3,73 & 3,77 & 3,79 \\
\hline 2 & TNDEV & 1,62 & 0,89 & 1,14 & 1,41 & 1,34 & 1,21 & 1,52 \\
\hline 3 & TNDEA & 3,00 & 3,27 & 1,15 & 1,22 & 1,46 & 0,95 & 1,38 \\
\hline 4 & TDEH & 0,76 & 0,89 & 1,09 & 0,81 & 0,94 & 0,87 & 0,90 \\
\hline 5 & TDEV & 1,48 & 1,27 & 1,07 & 1,26 & 1,63 & 1,24 & 0,97 \\
\hline
\end{tabular}

Overall vibrationtrendingditunjukkan seperti gambar berikut :

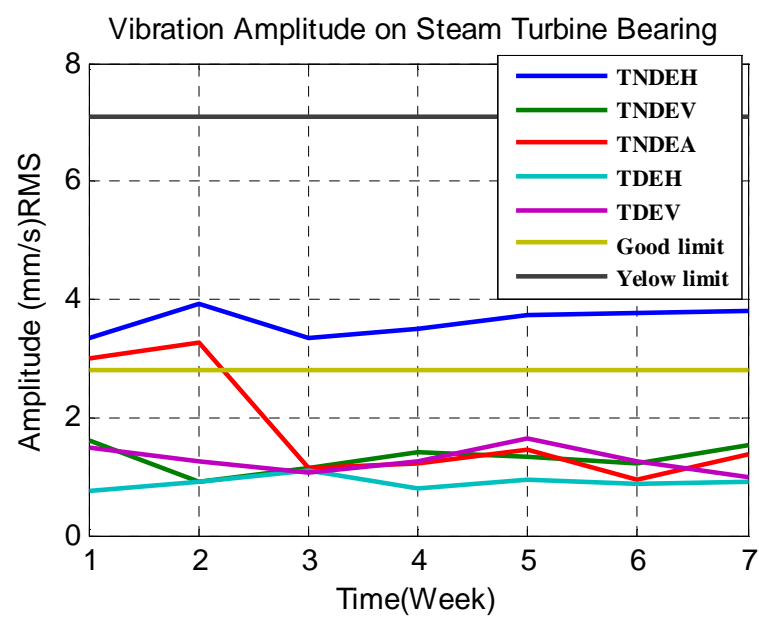

\section{Gambar 4.Trending amplitudo getaran pada turbin uap}

Overall amplitude pada bearing turbin uap secara keseluruhan dapat dikatakan relatif stabil. Berdasarkan vibration severity standard, turbin tersebut termasuk golongan IV. Kondisi turbin dikatakan masih bagus (good) jika amplitudonya kurang dari 2.8 $\mathrm{mm} / \mathrm{s}$ RMS. Dikatakan memuaskan jika amplitudonya lebih besar dari $2.8 \mathrm{~mm} / \mathrm{s}$ RMS sampai dengan $7.1 \mathrm{~mm} / \mathrm{s}$ RMS. Kondisi disebut tidak memuaskan jika amplitudonya dari $7.1 \mathrm{~mm} / \mathrm{s}$ RMS sampai $18.0 \mathrm{~mm} / \mathrm{s}$ RMS. Mesin dikatakan kondisi tidak diterima jika amplitudonya lebih besar dari $18.0 \mathrm{~mm} / \mathrm{s}$ RMS. Turbin uap yang diinspeksi kondisinya telah memasuki memuaskan dengan kata lain sudah memasuki peringatan I, karena bearing non drive end arah horisontal telah memasuki rentang amplitudo antara $2.8 \mathrm{~mm} / \mathrm{s}$ RMS dan $7.1 \mathrm{~mm} / \mathrm{s}$ RMS. Oleh karena itu diperlukan monitoring lebih intensif.

Untuk mengetahui penyebab utama getaran terjadi diperlukan analisa spektrum getaran.

\subsection{Sinyal getaran pada turbin}

Sinyal getaran pada turbine non drive end bearing ditunjukkan seperti gambar berikut: 


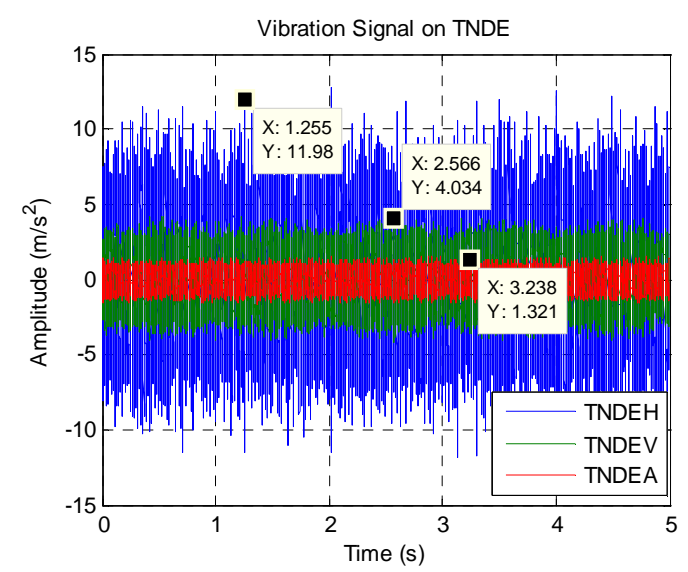

Gambar 5. Sinyal getaran pada TNDE

Sinyal getaran pada turbine drive end bearing ditunjukkan seperti gambar berikut:

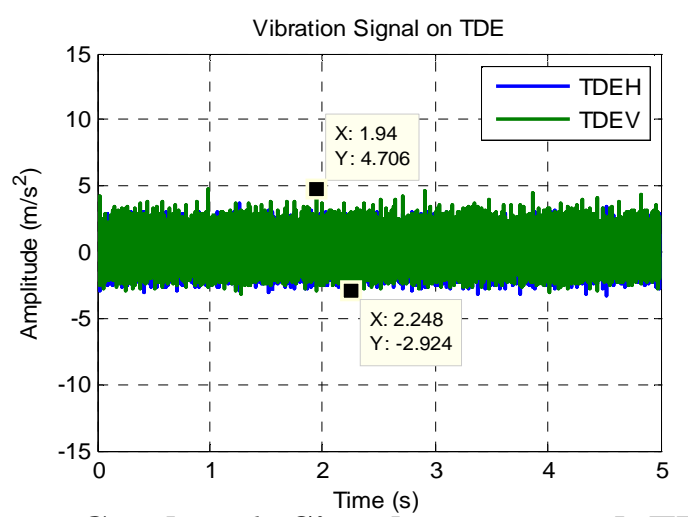

Gambar 6. Sinyal getaran padaTDE

Sinyal getaran pada turbine non drive bearing arah horisontal, vertikal dan aksial menunjukkan adanya impuls yang fluktuatif. Sinyal getaran juga menunjukkan amplitudo getaran yang terjadi pada arah horisontal menunjukkan yang tertinggi diikuti arah vertikal dan aksial dengan perbedaan yang signifikan. Sedangkan sinyal getaran pada turbine drive end bearing menunjukkan juga terjadinya impuls. Perbedaan amplitudo antara arah horisontal dan vertikal tidak signifikan.

Sinyal getaran tidak bisa digunakan untuk mengetahui sumber getaran yang terjadi. Untuk mengetahui sumber getaran yang terjadi diperlukan analisa spektrum getaran.

\subsection{Spektrum getaran pada turbin}

Spektrum getaran pada turbine non drive end bearing pada rentang frekuensi sampai dengan $10000 \mathrm{~Hz}$, ditunjukkan seperti pada gambar berikut.

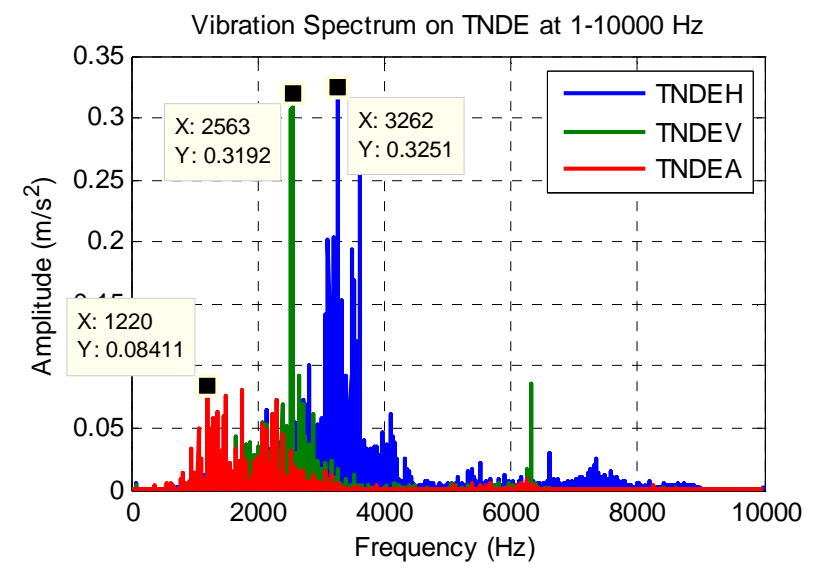

Gambar 7. Spektrum getaran pada TNDE

Spektrum getaran pada TNDE arah horisontal, vertikal dan aksial menunjukkan bahwa amplitudo tertinggi terletak pada frekuensi tinggi yaitu pada frekuensi 3262 Hz. Sedangkan pada frekuensi rendah yaitu di bawah $1000 \mathrm{~Hz}$ amplitudonya tidak tinggi. Hal ini menunjukkan bahwa masalah getaran yang terjadi bukan karena masalah instalasi turbin uap atau masalah mekanik, melainkan kemungkinan berasal dari transmisi kotak roda gigi. Getaran pada kotak roda gigi akan dibahas pada tulisan yang berbeda.

Untuk mengetahui karakteristik pada turbin uap, spektrum getaran diperjelas pada rentang frekuensi sampai dengan $500 \mathrm{~Hz}$, yang ditunjukkan seperti pada gambar berikut.

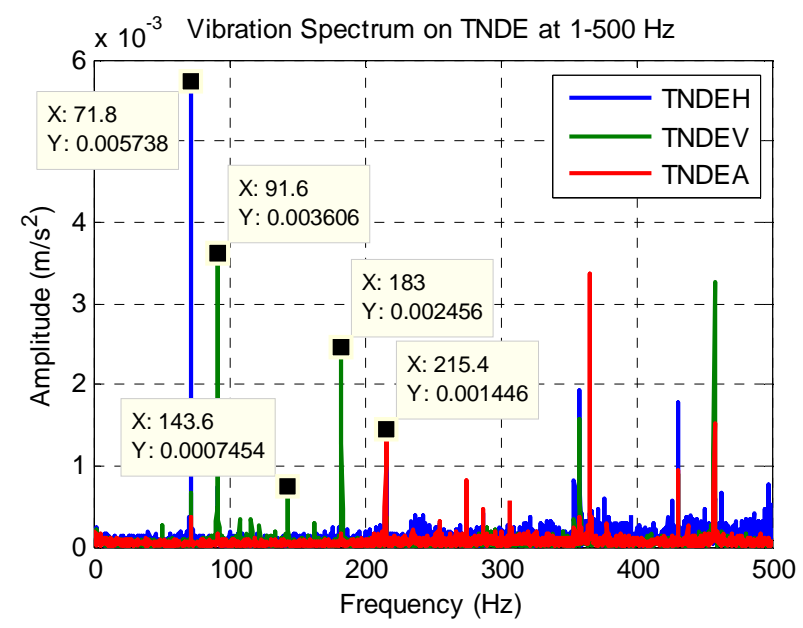

Gambar 8. Spektrum getaran pada TNDE rentang 1-500 Hz 
Pada spektrum getaran pada TNDE arah horisontal, vertikal dan aksial menunjukkan adanya frekuensi fundamental turbin dan frekuensi fundamental pompa berikut harmoniknya.

Untuk memperjelas letak frekuensi amplitudo tinggi dan frekuensi harmoniknya diperlukan pemisahan spektrum getaran setiap titik pengukuran. Vibration spektrum pada TNDEH dan TNDEV pada rentang frekuensi 1-500 Hz ditunjukkan seperti pada gambar.

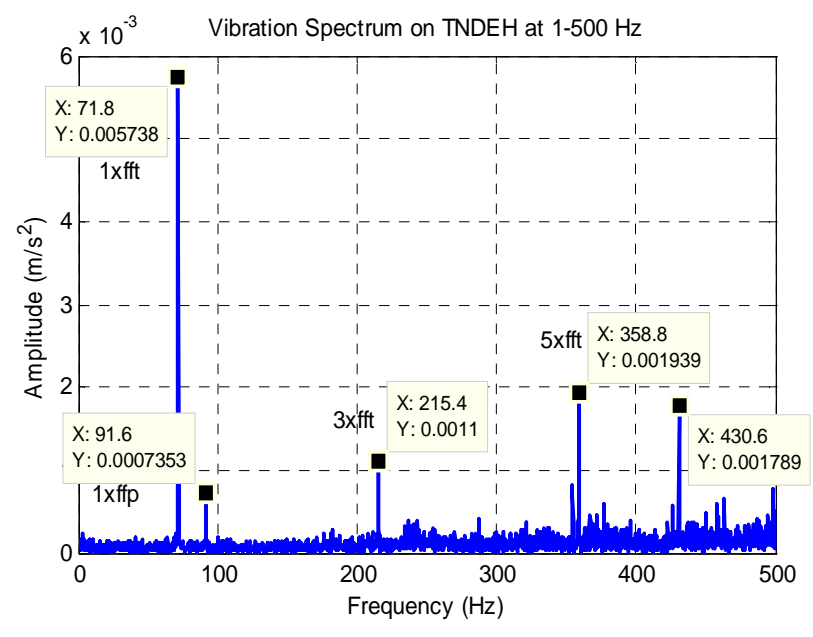

Gambar 9. Spektrum getaran pada TNDEH rentang $1-500 ~ H z$

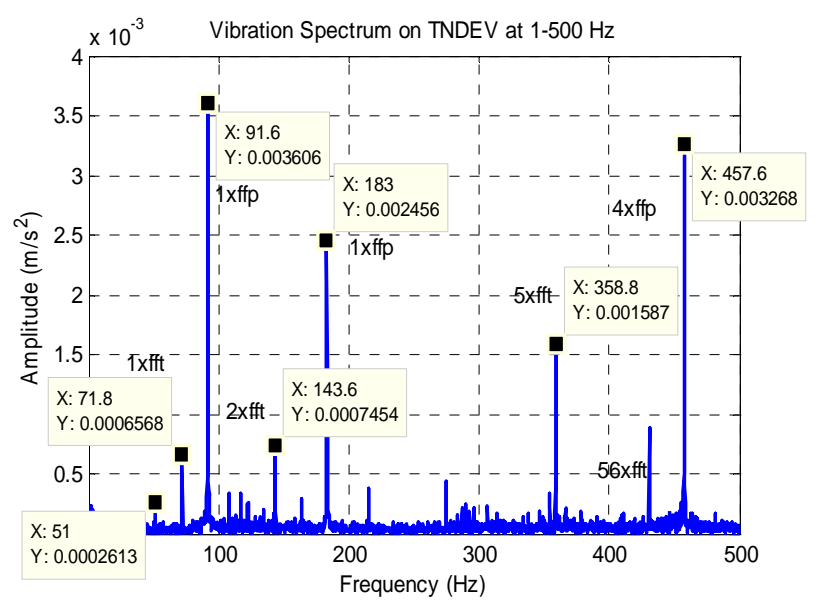

\section{Gambar 10. Spektrum getaran pada TNDEV rentang 1-500 $\mathrm{Hz}$}

Pada ke dua spektrum menunjukkan adanya frekuensi fundamental turbin yaitu $71.8 \mathrm{~Hz}$ dan frekuensi fundamental pompa yaitu 91.6 Hz. Hal ini menunjukkan bahwa putaran turbin sesungguhnya adalah $4308 \mathrm{rpm}$ dan putaran pompa sesungguhnya $5496 \mathrm{rpm}$.

Pada spektrum getaran tampak juga frekuensi harmonik turbin ke dua $143.6 \mathrm{~Hz}$ (2fft), frekuensi harmonik turbin ke tiga $215.4 \mathrm{~Hz}$ (3fft), frekuensi harmonik turbin ke empat $287.2 \mathrm{~Hz}$ (4fft), frekuensi harmonik turbin kelima $359.5 \mathrm{~Hz}$ (5fft) dan frekuensi harmonik turbin kelima $430.6 \mathrm{~Hz}$ (6fft). Walaupun demikian amplitudo di masing masing frekuensi berbeda beda.

Pada spektrum getaran juga tampak frekuensi fundamental atau frekuensi harmonik pompa pertama yaitu $91.6 \mathrm{~Hz}$ (1ffp), frekuensi harmonik pompa ke dua yaitu $183.2 \mathrm{~Hz}$ (2ffp), frekuensi harmonik pompa ke tiga yaitu $274.8 \mathrm{~Hz}$ (3ffp) dan frekuensi harmonik pompa ke empat yaitu $458.0 \mathrm{~Hz}$ (4ffp).

Pada spektrum getaran juga nampak amplitudo walaupun tidak tinggi yang terletak pada frekuensi $50 \mathrm{~Hz}$ jika dihubungkan dengan frekuensi fundamental turbin, frekuensi tersebut terletak pada $0.7 \mathrm{fft}$. Spektrum getaran pada turbine drive end bearing pada rentang frekuensi sampai dengan $10000 \mathrm{~Hz}$, ditunjukkan seperti pada gambar berikut.

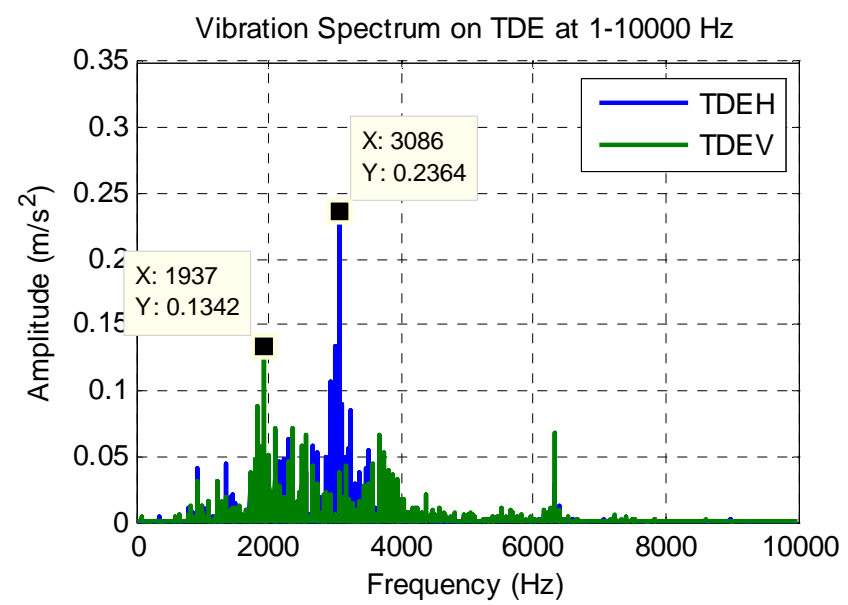

Gambar 11. Spektrum getaran pada TDE

Pada spektrum ini juga menunjukkan bahwa amplitudo tertinggi timbul pada frekuensi tinggi yaitu pada $3086 \mathrm{~Hz}$. Sedangkan pada frekuensi rendah kurang dari $1000 \mathrm{~Hz}$ amplitudonya tidak tinggi. Hal ini menunjukkan bahwa masalah terjadi bukan karena masalah instalasi turbin melainkan disebabkan karena instalasi kotak roda gigi. 
Agar spektrumnya lebih jelas rentang frekuensinya dipersempit dan dipisah setiap titik pengukuran. Vibration spektrum pada turbine drive end bearing arah horisontal dan vertikal rentang frekuensi $1-500 \mathrm{~Hz}$, ditunjukkan seperti pada gambar berikut.

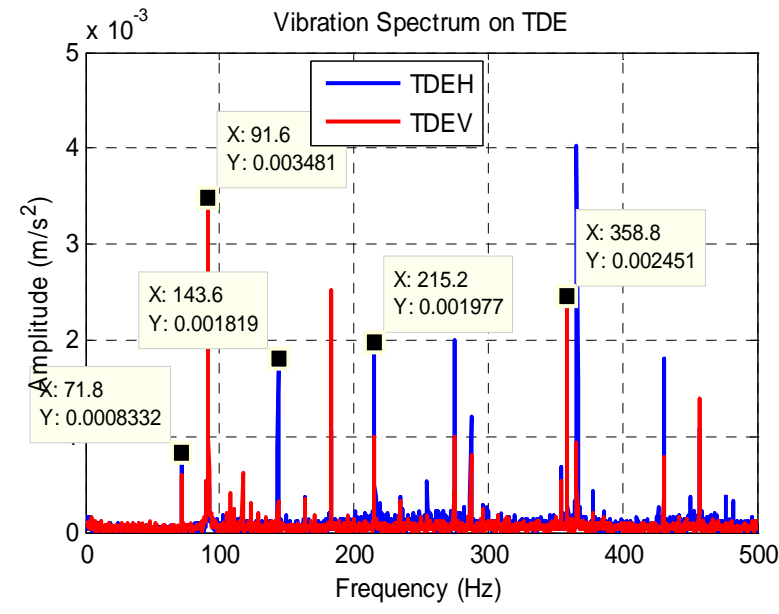

Gambar 12. Spektrum getaran pada TDE rentang 1-500 $\mathrm{Hz}$

Spektrum getaran di atas menunjukkan bahwa tampak frekuensi fundamental turbin yaitu pada $71.8 \mathrm{~Hz}$ dan frekuensi fundamental pompa pada $91.6 \mathrm{~Hz}$ serta harmonik dari frekuensi fundamental turbin dan pompa.

Untuk memperjelas frekuensi amplitudo berada, vibration spektrum pada turbine drive end bearing arah horisontal rentang frekuensi dipersempit menjadi $1-500 \mathrm{~Hz}$, ditunjukkan seperti pada gambar berikut.

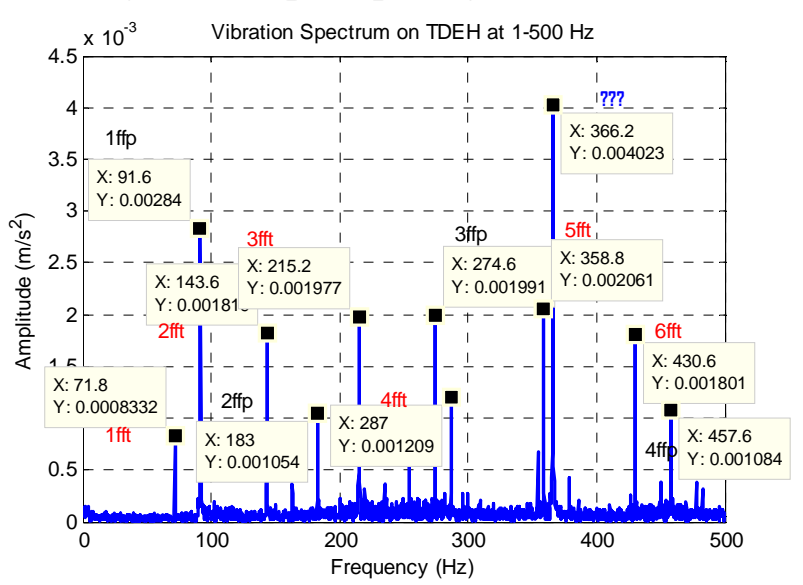

Gambar 13. Spektrum getaran pada

TDEH rentang 1-500 $\mathrm{Hz}$

Sedangkan gambar berikut menunjukkan spektrum getaran pada turbine drive end bearing arah vertikal rentang frekuensi 1-500 rpm.

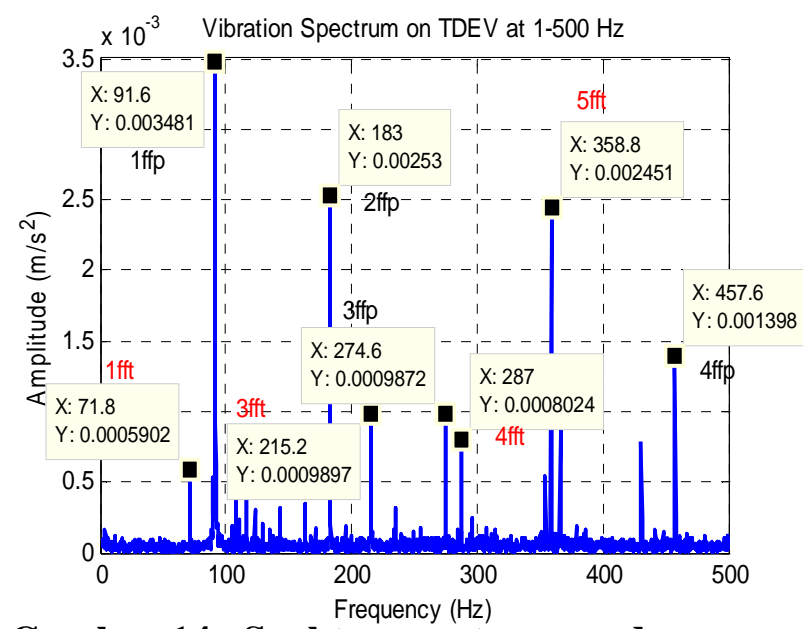

Gambar 14. Spektrum getaran pada TDEVrentang 1-500 Hz

Spektrum pada turbine drive end bearing arah horisontal dan vertikal menunjukkan adanya frekuensi fundamental turbin 71.8 $\mathrm{Hz}$, dan frekuensi fundamental pompa 91.6 Hz. Dalam gambar tersebut juga tampak harmonik dari frekuensi fundamental turbin dan pompa. Harmonik ke dua, ke tiga, ke empat, ke lima frekuensi fundamental turbin yaitu 143.6 (2fft), $215.4 \mathrm{~Hz}(3 \mathrm{fft}), 287.2 \mathrm{~Hz}$ (4fft) dan $359.5 \mathrm{~Hz}$ (5fft) serta $430.6 \mathrm{~Hz}$ (6fft). Harmonik ke dua, ke tiga, ke empat dari frekuensi fundamental pompa ditunjukkan oleh $183 \mathrm{~Hz}$ (2ffp), 274.6 Hz (3ffp) dan $457.6 \mathrm{~Hz}$ (4ffp). Dari gambar tersebut juga tampak frekuensi yang belum dapat diidentifkasi yaitu pada frekuensi 366.2 $\mathrm{Hz}$.

Amplitudo yang terjadi baik pada frekuensi fundamental turbin dan pompa, berikut harmonik pertama, ke dua, ke tiga, ke empat dan ke 5 menunjukkan karakteristik getaran karena masalah instalasi atau masalah mekanik. Sedangkan pada frekuensi 3262 $\mathrm{Hz}$ dan $366.2 \mathrm{~Hz}$, kemungkinan tidak berhubungan dengan karakteristik getaran karena mekanik, mungkin berasal dari gear meshing frequency. Oleh karena itu kajian akan dilanjutkan dengan pengukuran dan analisa getaran pada transmisi kotak roda gigi yang digunakan untuk menghubungkan antara turbin uap dan pompa. 


\section{Kesimpulan}

Dari uraian dan analisis data inspeksi getaran pada turbin uap dapat ditarik beberapa kesimpulan. Berdasarkan pengukuran averall amplitude disimpulkan bahwa kondisi turbin uap masih dalam kondisi baik (good) dan memasuki memuaskan (satisfactory), dalam istilah lain telah memasuki masih diperbolehkan (allowable) atau peringatan I. Berdasarkan analisis sinyal dan spektrum menunjukkan bahwa pada frekuensi rendah $<500 \mathrm{~Hz}$ tampak secara jelas frekuensi fundamental dari turbin dan pompa berikut frekuensi harmoniknya sampai $6 \mathrm{fft}$ dan 4 ffp.

Spektrum pada rentang $1-10000 \mathrm{~Hz}$ menunjukkan amplitudo tertinggi terletak pada frekuensi $3262 \mathrm{~Hz}$ kemungkinan berasal dari gear meshing frequency.

\section{Daftar Pustaka}

- Muin, S., A., 1993,Pesawat-pesawat Konversi Energi II (Turbin Uap),PT RajaGrafindo Persada, Jakarta.

- Thapliyal, A., 2017, What is the difference between electric centrifugal pump and normal centrifugal pump?,https://www.quora.com/Wha t-is-the-difference-between-electriccentrifugal-pump-and-normalcentrifugal-pump.
- Dresser Rand, 2011, Instruction Manual for Single Stage 350, 500 and 700 Frame Steam Turbine, Manual 107A, New York.

- Juan G., L., Hui Z., C., Min H., Yong Z., 2013, Vibration Analysis of the Steam Turbine Shafting caused by Steam Flow, Telkomika, Vol 11, No, 8, August.

- Ahmed, I., Islam, R., Sarkar, M.,A.,R., Haq, Z., 2016, Vibration Monitoring and Condition Analysis of a 210 MW Steam Turbine,International Conference of Mechanical, Industrial and Material Engineering, ICMIME 2015, Rajshah, Bangladesh.

- Elliot Group, 2014, YR Steam Turbine, Elliot Group Ebara Corporation.

- Elmaati H., Benbouaza, A., Elkihel, B., Delaunois, F., 2013, Implementation of a Vibration monitoring system of a steam turbine for optimization of the maintenance, International Journal of Emerging Trends and Technology in Computer Science (IJETTCS), Volume 2, Issue 6, November - December 2013.

- Reliability Direct, 2013, ISO 10816 Vibration Severity Chart, https://www.reliabilitydirectstore.co $\underline{\mathrm{m} / \mathrm{kb} \text { results.asp? } \mathrm{ID}=75}$ 